\title{
IMPLEMENTASI ALGORITME C4.5 UNTUK PREDIKSI PENANAMAN CABAI MERAH
}

\author{
Muhammad Syam Firdaus ${ }^{1}$, Aji Primajaya ${ }^{2}$, Asep Jamaludin ${ }^{3}$ \\ Program Studi Teknik Informatika, Universitas Singaperbangsa Karawang ${ }^{1,2,3}$ \\ muhammad.syam17155@student.unsika.ac.id
}

Submitted August 9, 2021; Revised November 25, 2021; Accepted November26, 2021

\begin{abstract}
Abstrak
Tanaman cabai menjadi tanaman yang paling banyak ditanam di Indonesia, karena tanaman ini dapat berbuah dan tumbuh di dataran tinggi maupun di dataran rendah. Setiap tahunnya permintaan pasar akan cabai terus meningkat, bahkan setiap tahunnya harga cabai cenderung meningkat yang di akibatkan pasokan cabai berkurang dan permintaan pasar kurang terpenuhi. Kegagalan panen yang dialami para petani cabai menyebabkan pertumbuhan inflasi di tahun 2020 sebanyak 0,31\% disumbang oleh naiknya harga di sektor pangan, termasuk di dalamnya cabai rawit dan cabai merah. Fluktuasi harga cabai ini sangat dipengaruhi cuaca, panen raya, kebijakan perdagangan dan momentum yang mengiringi. Sesuai dengan latar belakang, tujuan dari penelitian ini untuk memprediksi penanaman cabai menggunakan algoritme C4.5. pertama proses pengumpulan data cuaca dan harga dilakukan oleh peneliti yang diambil dari DISPERINDAG, BMKG dan data harga cabai di pasaran untuk dijadikan dataset, dataset dikumpulkan dilakukan preprosessing untuk menghilangkan missing value, outliers data dan juga imbalance data, lalu setelah itu dilanjutkan dengan tahap pembuatan model, dari model tersebut dapat memprediksi penanaman cabai. Hasil prediksi dengan menggunakan rule dari pohon keputusan yang di dapatkan mempunyai tingkat akurasi sebesar 97,8\% berdasarkan perhitungan dari prediksi menggunakan data validasi sebanyak 95 data.
\end{abstract}

Kata Kunci : Prediksi Penanaman Cabai, Algoritma C4.5, Klasifikasi, Data Mining

\begin{abstract}
Chili has been the most widely grown plant in Indonesia because it can bear fruit and grow in the highlands and the lowlands. Every year the market demand for chili continues to increase, even the annual price of chili tends to increase as a result of reduced chili supply and less fulfilled market demand. Besides, the crop failure experienced by chili farmers cause inflation growth in 2020 as much as $0.31 \%$, resulting from rising prices in the food sector, including the price of cayenne pepper and red chili. The fluctuations in chili prices are strongly influenced by weather, harvest season, trade policies and the accompanying momentum. According to the background, the purpose of this study is to predict chili planting using the C4.5 algorithm. First, the researchers collect weather and price data taken from DISPERINDAG, BMKG, use chili price data on the market as a dataset to be later preprocessed to eliminate missing values, data outliers and imbalance data and then make a model that can predict chili planting. The prediction results using the rule from the decision tree have an accuracy rate of $97.8 \%$ based on the calculation of the prediction using validation data as much as 95 data
\end{abstract}

Keywords : Chili Planting Prediction, C4.5 Algorithm, Classification, Data Mining

\section{PENDAHULUAN}

Tanaman cabai menjadi tanaman yang paling banyak ditanam di Indonesia, karena tanaman ini dapat berbuah dan tumbuh di dataran tinggi maupun di dataran rendah. Cabai biasa digunakan oleh orang Indonesia sebagai bumbu masakan dapur yang bercita rasa pedas. Setiap tahunnya permintaan pasar akan cabai terus meningkat, meningkatnya kebutuhan pasar dapat dilihat dari banyaknya makanan-makanan yang ada di Indonesia yang memerlukan bahan baku cabai sebagai pelengkap. Namun 
persediaan cabai yang minim mengakibatkan harga yang dipatok oleh petani atau pengepul menjadi mahal. Jika harga cabai melonjak tinggi dan kebutuhan pasar kurang terpenuhi maka akan menimbulkan inflasi [1].

Cabai yang rusak atau busuk dapat mengakibatkan kegagalan panen yang dialami oleh para petani cabai. Kegagalan panen tersebut menjadi salah satu faktor penyebab dari kurangnya pasokan cabai di Indonesia. Cabai yang rusak dan busuk tersebut diakibatkan iklim cuaca yang tidak mendukung sehingga buah tidak tumbuh dengan baik dan menyebabkan kekurangan pasokan pada akhir 2019 dan terus menunggak hingga akhir tahun 2020 [2].

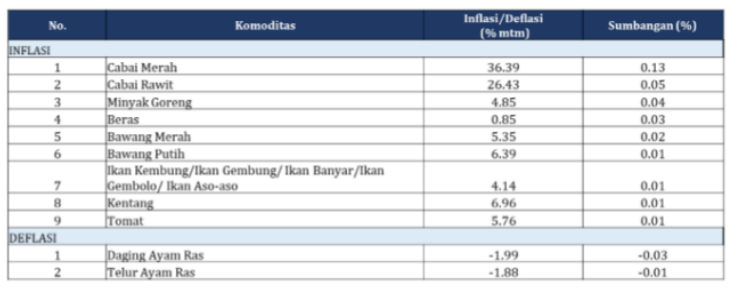

Gambar 1. Inflasi di Sektor Pangan

Sumber : Tim Pengendalian Inflasi Pusat (TPIP)

Kegagalan panen yang dialami para petani cabai menyebabkan pertumbuhan inflasi di tahun 2020 sebanyak 0,31\% disumbang oleh naiknya harga di sektor pangan, termasuk di dalamnya cabai rawit dan cabai merah. Kenaikan inflasi disumbang oleh cabai rawit yaitu menyumbang kenaikan sebesar 0,05 persen di satu sisi cabai merah menyumbang kenaikan sebesar 0,13 persen [3]. Perubahan cuaca ataupun iklim dapat mempengaruhi produksi cabai setiap tahunnya seperti penelitian yang telah dilakukan oleh Ridho (2020) dalam penelitiannya pada petani cabai di Kota Malang, Kecamatan Pakis. Penelitian tersebut menyebutkan di Kecamatan Pakis mengalami penurunan produksi buah cabai pada tahun 2015 sebesar 319,6 kilogram, yang sebelumnya pada tahun 2014 petani cabai dapat menghasilkan 505,5 kilogram buah cabai.
Tanaman cabai dapat menghasilkan buah cabai yang baik dan bagus apabila cara menanam tanaman cabai tersebut dapat disesuaikan dengan keadaan lingkungan.

Petani dapat membuat rencana sendiri untuk budidaya tanaman cabainya, agar dapat membuat perencanaan tersebut petani cabai memerlukan informasi cuaca. Cuaca menjadi salah satu penyebab besar yang mempengaruhi keberhasilan dalam budidaya tanaman cabai, pertumbuhan tanaman cabai akan baik jika petani cabai dapat mempersiapkan ladangnya seperti pengairan, bedengan dan jenis cabai sesuai dengan cuacanya. Cuaca sifatnya tidak dapat dikontrol oleh manusia, oleh karena itu petani hanya dapat mengantisipasinya dan menyesuaikan cara budidaya tanaman cabai berdasarkan dengan kondisi cuaca [5]. Waktu yang diperlukan untuk budidaya tanaman cabai cukup panjang, yaitu sekitar enam bulan dari pembibitan sampai masa panen [6] .Oleh karna itu informasi terhadap kondisi cuaca yang akan datang sangat diperlukan.

Algoritme C4.5 digunakan untuk mengklasifikasi keadaan cuaca dan harga yang nantinya akan menghasilkan berupa pohon keputusan, dari pohon keputusan tersebut akan menghasilkan sebuah rule atau aturan. Aturan yang didapatkan digunakan untuk memprediksi data cuaca dan harga sehingga dapat digunakan pengambilan keputusan untuk menanam cabai. Data cuaca yang digunakan menggunakan data penelitian sebelumnya oleh Rosdiana \& Rismayana (2018) yaitu data tahun 2011-2018 dan data terbaru dari tahun 2019 sebagai data tambahan untuk wilayah Bandung. Manfaat yang diharapkan dalam penulisan ini adalah dapat memprediksi keputusan penanaman cabai secara akurat dengan menggunakan algoritme C4.5. Penelitian ini mengacu pada penelitian sebelumnya oleh Rosdiana \& Rismayana (2018) yang memprediksi tanam cabai menggunakan algoritme C4.5 
dengan hasil akurasi yaitu $72.2 \%$ dengan kriteria akurasi baik menggunakan confusion matrix. Berdasarkan penelitian tersebut peneliti ingin melakukan penelitian serupa dengan menggunakan algoritme $\mathrm{C} 4.5$ dengan penanganan data seperti missing value, outliers data dan imbalance data serta pembagian data menggunakan $k$-fold cross validation agar menghindari terjadinya overfitting, lalu evaluasi dari model menggunakan confussion matrix dan mengharapkan dapat memprediksi penanaman cabai lebih baik lagi.

Berdasarkan permasalahan tersebut, penelitian untuk memprediksi penanaman cabai dibutuhkan sehingga diambillah judul penelitian "Implementasi Algoritme C4.5 dalam Memprediksi Penanaman Cabai Merah".

\section{METODE PENELITIAN}

\section{Teknik Pengumpulan Data}

Data diperoleh menggunakan teknik pengambilan data sekunder yaitu mengambil data dari situs Badan Meteorologi Klimatologi dan Geofisika (BMKG) (https://dataonline.bmkg.go.id/) dan Dinas Perindustrian dan Perdagangan (Disperindag)

(http://disperindag.jabarprov.go.id/) di wilayah Bandung, Jawa Barat. Data diambil dari tahun 2011 - 2019. Data yang diambil dari BMKG adalah data cuaca yang terdiri dari suhu rata-rata, kelembapan rata-rata, dan curah hujan, sedangkan data yang di ambil dari Disperindag berupa data harga lokal cabai merah di pasar tradisional. Deskripsi data tersebut dapat dilihat pada Tabel 1
Tabel 1. Deskripsi Data

\begin{tabular}{|c|c|c|c|}
\hline No & Atribut & Tipe Data & Keterangan \\
\hline 1 & Nama Stasiun & Kategorik & $\begin{array}{c}\text { Nama stasiun } \\
\text { Meteorologi }\end{array}$ \\
\hline 2 & WMO ID & Numerik & ID stasiun \\
\hline 3 & Tanggal & Numerik & $\begin{array}{c}\text { Data per hari } \\
\text { menggunakan } \\
\text { tanggal }\end{array}$ \\
\hline 4 & $\begin{array}{l}\text { Suhu rata-rata } \\
\qquad\left({ }^{\circ} \mathrm{C}\right)\end{array}$ & Numerik & $\begin{array}{c}\text { Suhu rata-rata } \\
\text { yang di ukur dan } \\
\text { di hitung rata-rata } \\
\text { berdasarkan } \\
\text { harian }\end{array}$ \\
\hline 5 & $\begin{array}{l}\text { Kelembapan } \\
\text { rata-rata }(\%)\end{array}$ & Numerik & $\begin{array}{c}\text { Kelembapan rata- } \\
\text { rata yang di ukur } \\
\text { dan di hitung rata- } \\
\text { rata berdasarkan } \\
\text { harian }\end{array}$ \\
\hline 6 & $\begin{array}{l}\text { Curah hujan } \\
(\mathrm{mm})\end{array}$ & Numerik & $\begin{array}{c}\text { Curah hujan yang } \\
\text { di ukur } \\
\text { berdasarkan } \\
\text { harian }\end{array}$ \\
\hline 7 & $\begin{array}{c}\text { Lamanya } \\
\text { penyinaran } \\
\text { matahari (jam) }\end{array}$ & Numerik & $\begin{array}{c}\text { Lamanya } \\
\text { matahari bersinar } \\
\text { yang di ukur } \\
\text { berdasarkan } \\
\text { harian }\end{array}$ \\
\hline 8 & Harga Jabar & Numerik & $\begin{array}{c}\text { Data Harga cabai } \\
\text { merah di Jawa } \\
\text { Barat }\end{array}$ \\
\hline 9 & Harga Lokal & Numerik & $\begin{array}{c}\text { Data Harga cabai } \\
\text { merah di pasar } \\
\text { tradisional di } \\
\text { wilayah Bandung }\end{array}$ \\
\hline 10 & $\begin{array}{c}\text { Label } \\
(\text { tanam/tidak) }\end{array}$ & Kategorik & $\begin{array}{c}\text { Label penanaman } \\
\text { cabai } \\
\text { perhariannya }\end{array}$ \\
\hline
\end{tabular}

Teknik Analisis dan Pemrosesan Data

Proses analisis dan pemrosesan data menggunakan tools jupyter notebook dan juga menggunakan bahasa pemrograman python. Penelitian ini menggunakan metode Knowledge Discovery in Database (KDD) untuk mengolah data. Knowledge Discovery in Database (KDD) merupakan metode cara memperoleh pengetahuan dari data yang ada. Data tersebut memiliki tabel yang berhubungan / terkoneksi. Pengetahuan yang diperoleh dalam proses ini dapat digunakan sebagai sumber pengetahuan untuk pengambilan keputusan [8]. Berikut adalah tahapan atau proses dalam penelitian ini pada Gambar 2. 


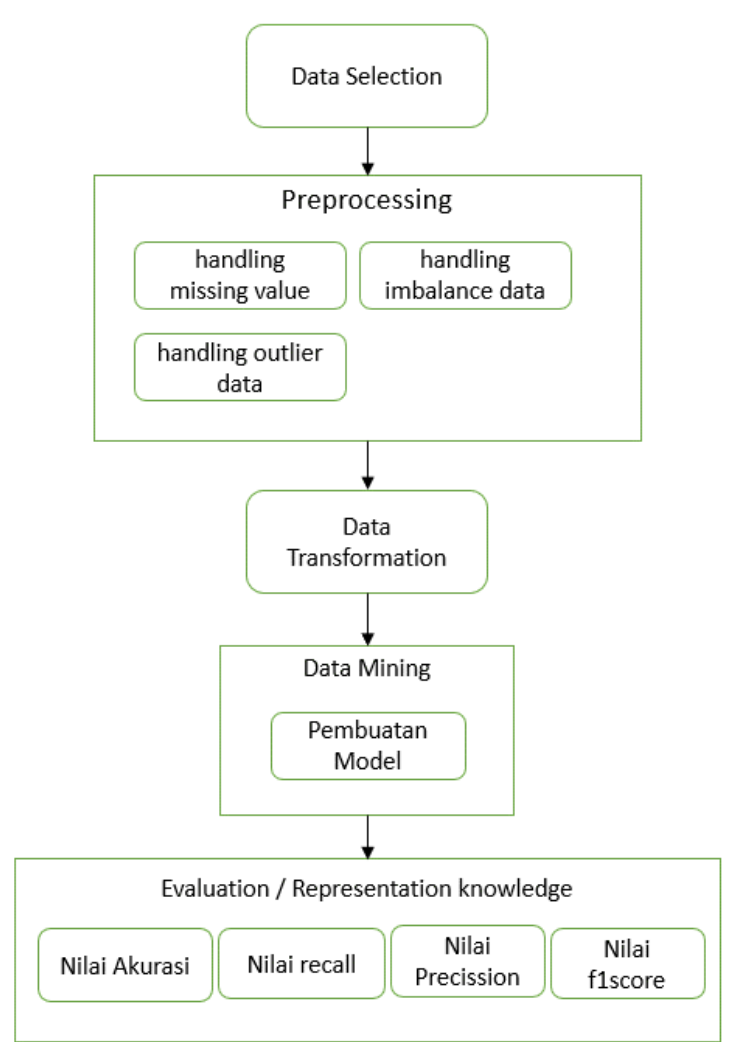

Gambar 2. Proses KDD

\section{Data Selection}

Penentuan basis data yang akan digunakan untuk prediksi merupakan tahapan pertama dalam data mining. Data yang akan digunakan adalah data penelitian sebelumnya yang berasal dari data BMKG dari tahun 2011 - 2019 di wilayah Bandung, Jawa Barat. Pada tahap seleksi data ini, data yang berasal dari basis data akan diseleksi, sehingga data yang sudah diseleksi tersebut akan dianalisis dan masuk ke tahap selanjutnya.

\section{Preprocessing}

Preprocessing merupakan salah satu tahap pada data mining yang akan menganalisis data dan melakukan pembersihan noise pada dataset, pembersihan data pada tahap data mining ini perlu dilakukan guna menyingkirkan data-data yang tidak diperlukan untuk proses prediksi nantinya, seperti data outlier, imbalance data ataupun missing value. Penanganan yang akan dilakukan terhadap missing value dan outliers data yaitu dengan menghapus sejumlah record yang terdapat missing value dan juga menghapus outliers data (data yang sebarannya terlalu jauh) lalu penanganan terhadap imbalance data akan digunakan pendekatan re-sampling

\section{Data transformation}

Menurut referensi [9] transformasi data adalah proses mentransformasi atau mengubah data ke dalam bentuk yang sesuai, agar dapat diproses. Dalam data transformation, terdapat beberapa operasi/teknik untuk melakukan transformasi data, yaitu smoothing, attribute construction, normalization, aggregation, dan discretization dan yang akan digunakan adalah discretization karena pada dataset penelitian data harus diubah dari data numerik menjadi kategorik.

\section{Data Mining}

Pada tahapan ini data yang sudah dipreprocessing akan diolah menggunakan metode dari data mining. Pada penelitian ini metode yang digunakan adalah C4.5 dengan proses yang telah dijelaskan sebelumnya. Nantinya data cuaca dan harga cabai tersebut akan dianalisis oleh sistem sehingga membentuk pohon keputusan dan dapat memprediksi penanaman cabai berdasarkan rule dari pohon keputusan tersebut.

5. Evaluation/Representation Knowledge Tujuan akhir dari tahap ini yaitu memproyeksikan informasi yang berguna bagi pengguna yang memakainya. Hasil akhir berupa model yang dibuat menggunakan algoritma C4.5, evaluasi yang dihasilkan oleh model yang ditraining yaitu berupa nilai akurasi, precission, recall dan f1score dari pengujian menggunakan decission tree classifier dan pembagian data menggunakan $k$-fold cross validation. 


\section{HASIL DAN PEMBAHASAN}

\section{Seleksi Data}

Tidak semua atribut pada data yang telah dikumpulkan digunakan untuk proses pengolahan data mining. Maka dilakukan proses data selection atau seleksi data yang bertujuan untuk menganalisis data-data yang relevan dan memilih atribut atau variabel yang berpengaruh pada data cuaca dan harga cabai dalam memprediksi penanaman tanaman cabai. Atribut pada data yang dipilih akan dioleh terlihat pada Tabel 2.

Tabel 2. Atribut Terpilih

\begin{tabular}{ccc}
\hline No & Atribut Terpilih & Detail Penggunaan \\
\hline 1 & Suhu rata-rata $\left({ }^{\circ} \mathrm{C}\right)$ & Atribut Penjelas \\
2 & Kelembapan rata-rata & Atribut Penjelas \\
& $(\%)$ & \\
3 & Curah hujan $(\mathrm{mm})$ & Atribut Penjelas \\
4 & Harga & Atribut Penjelas \\
5 & Label (tanam/tidak) & Atribut Target / Kelas \\
& & Target \\
\hline
\end{tabular}

Atribut suhu, kelembapan, dan curah hujan dipilih karena sangat berpengaruh terhadap pertumbuhan tanaman cabai, serta berpengaruh terhadap waktu penanaman cabai. Atribut yang tidak digunakan akan dihapus dan data yang terpilih akan diolah menggunakan algoritma klasifikasi yaitu algoritma C4.5 yang nantinya akan menghasilkan sebuah pohon keputusan, dan pohon tersebut akan menjadi rule, yang nantinya dapat memprediksi penanaman cabai.

\section{Data Preprocessing}

Preprocessing merupakan salah satu tahapan penting pada proses mining dikarenakan data yang digunakan dalam proses mining tidak selamanya dalam kondisi yang ideal untuk diproses terkadang pada data tersebut terdapat berbagai permasalahan yang dapat mengganggu hasil dari proses mining itu sendiri diantarainya seperti missing value, outliers, dan imbalance data. Setelah melihat dan menganalisis data yang ada pada tahapan data preprocessing dengan data yang ada yaitu data penelitian sebelumnya yang telah diseleksi dan ternyata harus dilakukan penanganan terhadap outliers data, missing value dan juga penanganan imbalance data.

a. Penanganan Outliers Data

Pada dataset yang sudah diseleksi, data memiliki outliers yang perlu ditangani, outliers pada dataset dapat dilihat pada atribut pada Tabel 3.

Tabel 3. Outliers Data

\begin{tabular}{cccc}
\hline Nama Atribut & Min & Max & Average \\
\hline Suhu & 21 & 26 & 23.5 \\
Kelembapan & 20 & 8888 & 4454 \\
Curah Hujan & 0 & 8888 & 4444 \\
Harga & 21000 & 94000 & 57500 \\
\hline
\end{tabular}

Data yang outliers dapat divisualisasikan melalui grafik, salah satunya adalah scatter plot, sebaran data harga terhadap suhu dapat dilihat pada Gambar 3.

\section{Gambar 3. Sebaran Data Atribut Harga}

Pada Gambar 3 terlihat harga memiliki sebaran data yang padat, akan tetapi data tersebut memiliki outliers data, yang sebarannya terlalu jauh, data tersebutlah yang harus ditangani agar data tidak memiliki noise yang nantinya akan berpengaruh terhadap model data mining. Penanganan pada outliers data tersebut adalah, dengan menghapus range yang terlalu jauh, seperti max value pada atribut kelembapan dan curah hujan yang bernilai 
8888, lalu pada atribut harga dengan range antara 25000 - 72000 saja sisanya yang melebihi range tersebut akan dihapus. Setelah melalui tahap outliers data, jumlah dataset menjadi 785.

b. Penanganan Missing Value

Pada dataset yang sudah diseleksi, ternyata masih memiliki missing value pada atribut suhu, kelembapan dan juga curah hujan, dapat dilihat keterangan missing value pada atribut pada Gambar 4

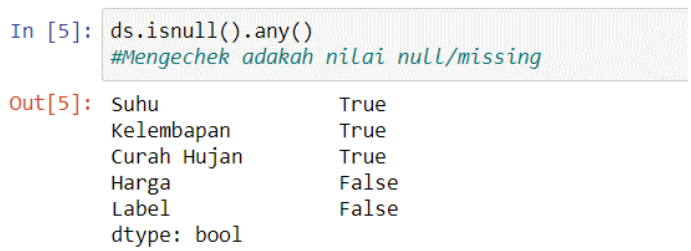

Gambar 4. Missing Value

Penanganan pada data missing value tersebut yaitu peneliti menggunakan nilai rata-rata setiap bulannya, misalkan ada data missing pada atribut suhu pada bulan juni tahun 2014, berarti tinggal dirataratakan nilai suhu pada bulan juni tahun 2014 lalu isi kolom yang missing tersebut pada atribut suhu.

c. Penanganan Imbalance Data

Dataset setelah diteliti kembali ternyata memiliki ketidakseimbangan data, terdeteksi bahwa data yang memiliki label "tanam" memiliki jumlah data yaitu sebanyak 360, sedangkan label "tidak" memiliki jumlah data lebih banyak yaitu sebanyak 421. Penanganan yang peneliti lakukan adalah dengan melakukan pendekatan re-sampling yaitu undersampling. Cara under-sampling dalam menangani imbalance data ini yaitu dengan cara mengurangi data pada class yang besar agar seimbang dengan class yang kecil, akan tetapi memiliki ketentuan yaitu hanya dapat dilakukan apabila jumlah data antar class tidak terlalu jauh agar cara tersebut efektif. Pada penelitian ini dataset antar classnya memiliki selisih yang tidak terlalu jauh sehingga bisa menggunakan cara under-sampling ini dengan mengurangi class yang besar yaitu class "tidak", sehingga saat ini dataset yang digunakan sama-sama memiliki 360 jumlah data setiap class-nya.

\section{Data Transformation}

Tahapan transformation merupakan tahapan perubahan data ke dalam bentuk sesuai yang diinginkan dengan kebutuhan yang ada. Pada dataset data yang akan dilakukan transformasi yaitu pada atribut label dikarenakan pada proses evaluasi pada python label harus menggunakan numerik.

Tabel 4. Perubahan Data pada Atribut Label

\begin{tabular}{ccc}
\hline No & Label & Perubahan \\
\hline 1 & Tanam & 1 \\
2 & Tidak & 0 \\
\hline
\end{tabular}

Perubahan tersebut akan diterapkan pada dataset yang memiliki jumlah 360 class "tanam" diganti menjadi nilai 1 , dan 360 lainnya dengan class "tidak" diganti menjadi nilai 0 .

\section{Data Mining}

Data telah melewati beberapa tahap diantaranya tahap selection, preprocessing, dan transformation kemudian dilakukan permodelan. Teknik pemodelan data mining yang dipilih adalah klasifikasi prediksi dengan menggunakan algoritma C4.5. Klasifikasi algoritma $\mathrm{C} 4.5$ digunakan untuk mencapai tujuan awal penelitian yaitu memprediksi penanaman cabai.

Implementasi algoritma C4.5 menggunakan bahasa pemrograman python dengan bantuan IDE atau text editor jupyter notebook guna membuat model klasifikasi dengan metode C4.5 dan juga dapat memprediksi penanaman cabai. Model yang dibuat menggunakan Decission tree classifier, sebuah library dari sklearn yang dapat memproses data 
menggunakan algoritma decission tree, lalu data akan dibagi menjadi data uji dan data latih. Pembagian data uji dan data latih tersebut menggunakan kfolds cross validation dengan nilai $\mathrm{k}=10$, sehingga nantinya akan terdapat 10 skenario pengujian dengan data uji dan data latih yang berbeda beda. Proses split data menggunakan kfolds cross validation dengan nilai $\mathrm{k}=10$ yang berarti terdapat 10 skenario pengujian. Terdapat 10 skenario pengujian dengan data uji dan data latih yang berbeda-beda. Berikut adalah penjelasan mengenai skenario yang dilakukan. Berikut adalah contoh untuk skenario pertama:

1. Skenario 1

Tabel 5. Hasil Prediksi Skenario 1

\begin{tabular}{ccc}
\hline & Actual Tanam & Actual Tidak \\
\hline Pred. Tanam & 36 & 0 \\
Pred. Tidak & 0 & 36
\end{tabular}

Berdasarkan hasil pada Tabel 5 terlihat bahwa sebanyak 36 data diprediksi "Tanam" dengan valid kemudian 36 data diklasifikasikan "Tidak" dengan valid. Setelah diketahui hasil dari prediksi tersebut, maka dapat diketahui nilai accuracy, recall, precision dan flscore.

$$
\begin{aligned}
\text { accuracy } & =\frac{T P+T N}{T P+T N+F P+F N} \\
& =\frac{36+36}{72}=1
\end{aligned}
$$

Precission, recall dan f1score class tanam pada skenario 1

$$
\begin{aligned}
& \text { precission }=\frac{T P}{T P+F P}=\frac{36}{36+0}=1 \\
& \text { recall }=\frac{T P}{T P+F N}=\frac{36}{36+0}=1
\end{aligned}
$$

$$
f 1 \text { score }=\frac{2 * \text { recall } * \text { precission }}{\text { recall }+ \text { precission }}=\frac{2 * 1 * 1}{1+1}=1
$$

Precission, recall dan flscore class tidak pada skenario 1

$$
\begin{aligned}
& \text { precission }=\frac{T P}{T P+F P}=\frac{36}{36+0}=1 \\
& \text { recall }=\frac{T P}{T P+F N}=\frac{36}{36+0}=1 \\
& f 1 \text { score }=\frac{2 * \text { recall } * \text { precission }}{\text { recall }+ \text { precission }}=\frac{2 * 1 * 1}{1+1}=1
\end{aligned}
$$

Dalam skenario pertama ini mendapatkan akurasi sempurna, jika dapat memprediksi semuanya maka precisson, recall dan f1score pun akan bernilai sama. Terdapat 10 skenario pengujian yang dilakukan pada penelitian ini, penulis hanya menjelaskan detail pada skenario pertama saja, selanjutnya skenario 2 sampai skenario 10 cara dan rumusnya sama persis dengan skenario pertama namun hasil akurasi, precission, recall dan f1score berbeda karna setiap skenario memiliki data uji dan data latih yang berbeda-beda. Berikut adalah hasil evaluasi dari 10 skenario pengujian pada Tabel 6.

Tabel 6. Hasil Evaluasi

\begin{tabular}{ccccc}
\hline Sk & Akurasi & Precission & Recall & F1score \\
\hline 1 & 1 & 1 & 1 & 1 \\
2 & 1 & 1 & 1 & 1 \\
3 & 1 & 1 & 1 & 1 \\
4 & 1 & 1 & 1 & 1 \\
5 & 0.98611111 & 0.97297297 & 1 & 0.98630137 \\
6 & 1 & 1 & 1 & 1 \\
7 & 0.97222222 & 0.94736842 & 1 & 0.97297297 \\
8 & 0.98611111 & 0.97297297 & 1 & 0.98630137 \\
9 & 1 & 1 & 1 & 1 \\
10 & 1 & 1 & 1 & 1 \\
\hline
\end{tabular}

Keterangan:

SK $=$ Skenario 
Terlihat pada Tabel 6, selain skenario 5, 7, 8 memiliki nilai akurasi, precission, recall, dan flscore yang sempurna, akan tetapi model yang dibuat belum tentu sempurna, setelah melakukan skenario terhadap cross validation, maka seluruh proses dari skenario pertama sampai akhir dirataratakan tingkat akurasinya dari proses cross validation tersebut, dan hasil akurasi rata ratanya adalah 0.9944444 , precission mendapatkan skor rata-rata 0,989331436, recall mendapatkan nilai rata-rata 1 dan f1score mendapatkan score rata-rata 0,994557571 .

\section{Evaluasi}

Penelitian ini dilakukan menggunakan metodologi KDD (Knowledge Discovery in Database) yang memiliki tahapan lima yaitu, data selection, data processing, transformation, data mining, dan evaluation. Dari skenario yang sudah dilakukan, algoritma C4.5 menghasilkan suatu pemodelan pohon keputusan yang berupa beberapa rule atau aturan untuk

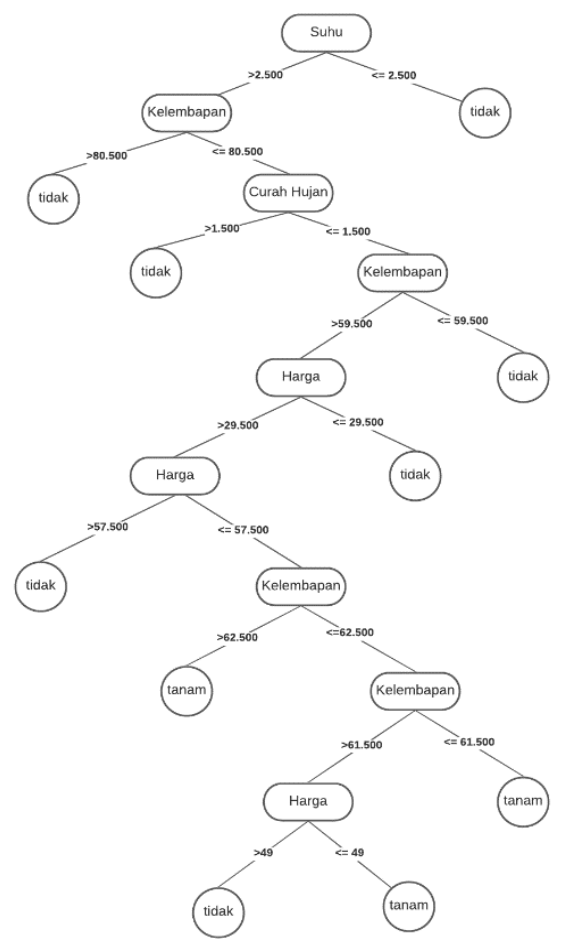

penelitian ini.

Gambar 5. Pohon Keputusan
Berdasarkan pohon keputusan tersebut yang dibangun oleh algoritma C4.5 mengenai prediksi tanam cabai di wilayah Bandung, Jawa Barat, menghasilkan sejumlah aturan atau rule sebagai berikut:

a. JIKA Suhu $<=2.500$ Maka tidak

b. JIKA Suhu > 2.500 dan Kelembapan > 80.500 MAKA tidak

c. JIKA Suhu > 2.500 dan Kelembapan <= 80.500 dan Curah Hujan > 1.500 MAKA tidak

d. JIKA Suhu $>2.500$ dan Kelembapan $<=$ 80.500 dan Curah Hujan $<=1.500$ dan Kelembapan $<=59.500$ MAKA tidak

e. JIKA Suhu $>2.500$ dan Kelembapan $<=$ 80.500 dan Curah Hujan $<=1.500$ dan Kelembapan > 59.500 dan Harga $<=29.500$ MAKA tidak

f. JIKA Suhu $>2.500$ dan Kelembapan $<=$ 80.500 dan Curah Hujan $<=1.500$ dan Kelembapan > 59.500 dan Harga $>29.500$ dan Harga > 57.500 MAKA tidak

g. JIKA Suhu $>2.500$ dan Kelembapan <= 80.500 dan Curah Hujan $<=1.500$ dan Kelembapan > 59.500 dan Harga $>29.500$ dan Harga $<=57.500$ dan Kelembapan $>62.500$ MAKA tanam

h. JIKA Suhu $>2.500$ dan Kelembapan $<=$ 80.500 dan Curah Hujan $<=1.500$ dan Kelembapan > 59.500 dan Harga $>29.500$ dan Harga $<=57.500$ dan Kelembapan $<=62.500$ dan Kelembapan $<=61.500$ MAKA tidak

i. JIKA Suhu $>2.500$ dan Kelembapan <= 80.500 dan Curah Hujan $<=1.500$ dan Kelembapan > 59.500 dan Harga $>29.500$ dan Harga $<=57.500$ dan Kelembapan $<=\quad 62.500$ dan Kelembapan > 61.500 dan Harga > 49 MAKA tidak

j. JIKA Suhu $>2.500$ dan Kelembapan $<=$ 80.500 dan Curah Hujan $<=1.500$ dan Kelembapan > 59.500 dan Harga $>29.500$ dan Harga $<=57.500$ dan Kelembapan $<=\quad 62.500$ dan Kelembapan $>61.500$ dan Harga $<=49$ MAKA tanam 
Setalah mendapatkan rule, selanjutnya akan dilakukan uji coba teradap model tersebut menggunakan sample data baru yang belum diketahui prediksinya. Sampel yang digunakan yaitu data cuaca dan harga tahun 2020.

Uji coba dilakukan menggunakan python dengan pengetesan dilakukan dengan menggunakan data lain. Hasil percobaan tersebut diketahui jika pemodelan yang dihasilkan algoritma C4.5 dapat memprediksi 95 data baru tersebut dengan memberikan keterangan berupa penanaman cabai, data baru tersebut merupakan data yang dibagi pada dataset sebelumnya.

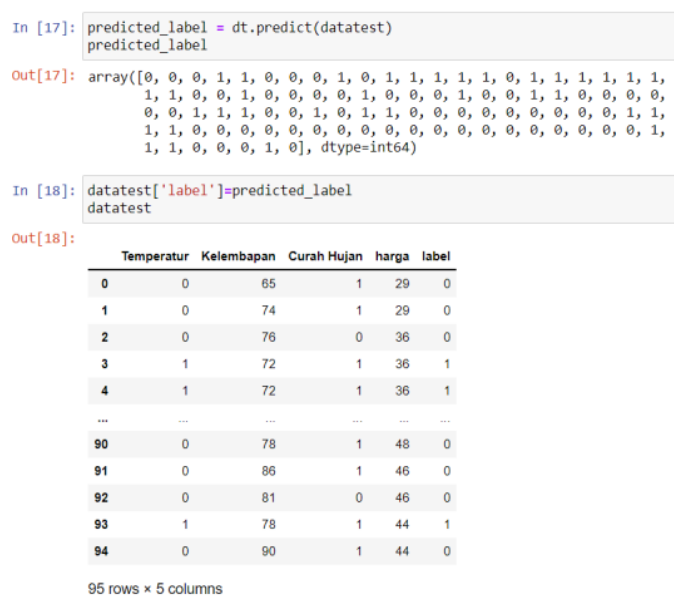

\section{Gambar 6. Hasil Prediksi Data Baru}

Hasil prediksi menggunakan 95 data baru pada tahun 2020 yang sudah dihapus labelnya, pada sistem mendeteksi terdiri dari 60 terprediksi tidak tanam, dan 35 terprediksi tanam. Pada Gambar 6 terlihat label masih menggunakan tipe data numerik, angka 0 menunjukkan bahwa sistem memprediksi class "tidak" sedangkan angka 1 menunjukkan bahwa sistem memprediksi class "tanam". Berikut hasil prediksi data yang baru disandingkan dengan label aktualnya.
Tabel 7. Hasil Prediksi Validasi Data

\begin{tabular}{|c|c|c|c|c|c|c|}
\hline No & Suhu & Klmbp & $\mathbf{C H}$ & Hrg & LA & LP \\
\hline 1 & 23.6 & 65 & 0 & 28.75 & tidak & tidak \\
\hline 2 & 23.5 & 74 & 0 & 28.75 & tidak & tidak \\
\hline 3 & 23.8 & 76 & 29.3 & 36 & tidak & tidak \\
\hline 4 & 24.3 & 72 & 0 & 36 & tanam & tanam \\
\hline 5 & 24 & 72 & 0 & 36 & tanam & tanam \\
\hline 6 & 23.7 & 68 & 0 & 36 & tidak & tidak \\
\hline 7 & 23.3 & 70 & 0 & 36 & tidak & tidak \\
\hline 8 & 23.8 & 72 & 0 & 37.5 & tidak & tidak \\
\hline 9 & 24.6 & 70 & 0 & 35.65 & tanam & tanam \\
\hline 10 & 23.4 & 77 & 1.9 & 36.9 & tidak & tidak \\
\hline 11 & 24.2 & 71 & 0 & 36.25 & tanam & tanam \\
\hline 12 & 24 & 72 & 0 & 36.25 & tanam & tanam \\
\hline 13 & 24.5 & 73 & 0.8 & 36.25 & tanam & tanam \\
\hline 14 & 24.7 & 71 & 0 & 36.25 & tanam & tanam \\
\hline 15 & 24.5 & 63 & 0 & 36.25 & tanam & tanam \\
\hline 16 & 23.6 & 68 & 0 & 36.25 & tidak & tidak \\
\hline 17 & 24.3 & 65 & 0 & 36.25 & tanam & tanam \\
\hline 18 & 24.5 & 70 & 0 & 35.4 & tanam & tanam \\
\hline 19 & 25.1 & 66 & 0 & 35.4 & tanam & tanam \\
\hline 20 & 25.2 & 69 & 0 & 35.4 & tanam & tanam \\
\hline 21 & 25.9 & 61 & 0 & 35.4 & tanam & tanam \\
\hline 22 & 24.6 & 64 & 0 & 36.65 & tanam & tanam \\
\hline 23 & 24 & 52 & 0 & 35.9 & tidak & tidak \\
\hline 24 & 24.3 & 64 & 0.3 & 35 & tanam & tanam \\
\hline 25 & 22.6 & 74 & 0.9 & 35 & tidak & tidak \\
\hline 26 & 23.6 & 62 & 0 & 35 & tidak & tidak \\
\hline 27 & 24.3 & 68 & 0 & 35 & tanam & tanam \\
\hline 28 & 23.1 & 79 & 12 & 35 & tidak & tidak \\
\hline 29 & 23.3 & 81 & 12.9 & 35 & tidak & tidak \\
\hline 30 & 23.5 & 81 & 1.3 & 35 & tidak & tidak \\
\hline 31 & 21.9 & 91 & 4.2 & 34.5 & tidak & tidak \\
\hline 32 & 24.3 & 79 & 10.7 & 34.5 & tanam & tanam \\
\hline 33 & 23.5 & 80 & 1.8 & 34.5 & tidak & tidak \\
\hline 34 & 23.8 & 80 & 56 & 34.5 & tidak & tidak \\
\hline 35 & 24.2 & 81 & 13.3 & 34.5 & tidak & tidak \\
\hline 36 & 24.2 & 79 & 13 & 34.15 & tanam & tanam \\
\hline 37 & 22.8 & 87 & 7.8 & 34.15 & tidak & tidak \\
\hline 38 & 23.7 & 77 & 39.1 & 34.15 & tidak & tidak \\
\hline 39 & 24.7 & 76 & 0 & 35.65 & tanam & tanam \\
\hline 40 & 25.3 & 71 & 0 & 37.75 & tanam & tanam \\
\hline 41 & 22.1 & 86 & 0 & 37.75 & tidak & tidak \\
\hline 42 & 23.6 & 78 & 25.9 & 37.75 & tidak & tidak \\
\hline 43 & 22.9 & 85 & 0.1 & 44.15 & tidak & tanam \\
\hline 44 & 23.9 & 83 & 20.5 & 44.15 & tidak & tidak \\
\hline
\end{tabular}




\begin{tabular}{|c|c|c|c|c|c|c|}
\hline 45 & 23.2 & 83 & 2 & 44.15 & tidak & tidak \\
\hline 46 & 24 & 75 & 20 & 44.15 & tidak & tidak \\
\hline 47 & 24.2 & 76 & 0 & 44.15 & tanam & tanam \\
\hline 48 & 25.6 & 67 & 5.8 & 44.15 & tanam & tanam \\
\hline 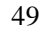 & 24.3 & 72 & 0 & 44.15 & tanam & tanam \\
\hline 50 & 22.8 & 84 & 0 & 40 & tidak & tidak \\
\hline . & 23.5 & 85 & 7.5 & 38.25 & tidak & tidak \\
\hline 52 & 24.1 & 80 & 19.8 & 37.75 & tanam & tanam \\
\hline 53 & 23.2 & 85 & 34 & 37.9 & tidak & tidak \\
\hline 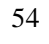 & 24.5 & 75 & 9.7 & 37.9 & tanam & tanam \\
\hline 55 & 24.2 & 75 & 0.3 & 37.9 & tanam & tanam \\
\hline 56 & 23.2 & 79 & 0.5 & 37.9 & tidak & tidak \\
\hline 57 & 22.3 & 80 & 26 & 35.9 & tidak & tidak \\
\hline 58 & 24 & 78 & 36 & 35.9 & tidak & tidak \\
\hline 59 & 23.7 & 80 & 12.8 & 34.5 & tidak & tidak \\
\hline 60 & 22.8 & 89 & 7.4 & 34.5 & tidak & tidak \\
\hline 61 & 23.3 & 84 & 13 & 34.5 & tidak & tidak \\
\hline 62 & 22.2 & 90 & 34.7 & 34.5 & tidak & tidak \\
\hline 63 & 23.4 & 86 & 8.8 & 34.5 & tidak & tidak \\
\hline 64 & 23.9 & 77 & 0.3 & 34.15 & tidak & tidak \\
\hline 65 & 25.3 & 69 & 0 & 35 & tanam & tidak \\
\hline 66 & 24.1 & 56 & 0 & 35 & tidak & tidak \\
\hline 67 & 24 & 71 & 0 & 35 & tanam & tanam \\
\hline 68 & 24.6 & 74 & 0 & 35 & tanam & tanam \\
\hline 69 & 23.4 & 87 & 0.4 & 35 & tidak & tidak \\
\hline 70 & 23.2 & 86 & 13.7 & 35 & tidak & tidak \\
\hline 71 & 23.1 & 89 & 26.5 & 36.25 & tidak & tidak \\
\hline 72 & 22.1 & 92 & 38.5 & 36.25 & tidak & tidak \\
\hline 73 & 22.8 & 83 & 15.8 & 36.25 & tidak & tidak \\
\hline 74 & 22.5 & 88 & 2.3 & 36.25 & tidak & tidak \\
\hline 75 & 21.6 & 90 & 65 & 36.25 & tidak & tidak \\
\hline 76 & 23.7 & 83 & 50.6 & 42.25 & tidak & tidak \\
\hline 77 & 23.8 & 80 & 32.7 & 42.25 & tidak & tidak \\
\hline $7 \varepsilon$ & 21.9 & 91 & 16.2 & 42.25 & tidak & tidak \\
\hline 79 & 23.1 & 83 & 17.3 & 42.25 & tidak & tidak \\
\hline 80 & 23.5 & 85 & 23.6 & 42.25 & tidak & tidak \\
\hline 81 & 23.2 & 84 & 1.6 & 44.65 & tidak & tidak \\
\hline 82 & 22.2 & 88 & 42 & 46.9 & tidak & tidak \\
\hline 83 & 23.1 & 84 & 8.5 & 46.9 & tidak & tidak \\
\hline 84 & 22.7 & 86 & 5.7 & 46.9 & tidak & tidak \\
\hline 85 & 22.8 & 82 & 10.9 & 46.65 & tidak & tidak \\
\hline 86 & 23.2 & 79 & 5 & 46.65 & tidak & tidak \\
\hline 87 & 23.5 & 87 & 13.2 & 46.65 & tidak & tidak \\
\hline 88 & 24.7 & 75 & 5.8 & 46.65 & tanam & tanam \\
\hline 89 & 24.7 & 69 & 0 & 41.25 & tanam & tanam \\
\hline a & 24 & 71 & 7 & 48.25 & tanam & tanam \\
\hline
\end{tabular}

\begin{tabular}{lllllll}
91 & 23.5 & 78 & 0 & 48.25 & tidak & tidak \\
92 & 22.8 & 86 & 7.2 & 45.9 & tidak & tidak \\
93 & 23.1 & 81 & 34.8 & 45.9 & tidak & tidak \\
94 & 24 & 78 & 0.5 & 44 & tanam & tanam \\
95 & 21.7 & 90 & 9.2 & 44 & tidak & tidak \\
\hline
\end{tabular}

Keterangan:

$\begin{array}{ll}\text { Klmbp } & =\text { Kelembapan } \\ \mathrm{CH} & =\text { Curah Hujan } \\ \mathrm{Hrg} & =\text { Harga } \\ \mathrm{LA} & =\text { Label Aktual } \\ \mathrm{LP} & =\text { Label Prediksi }\end{array}$

Setelah disandingkan dengan label aktualnya lihat dengan seksama label yang diprediksi oleh sistem hampir sama persis, namun dalam prediksi tersebut memiliki 2 kesalahan yaitu pada nomor 65 dan 43 yang tidak sama dengan label sebenarnya dan 93 data sisanya terprediksi dengan baik yang artinya sistem dapat memprediksi penanaman cabai dengan baik. Pada tes menggunakan validation data ini untuk menunjukkan bahwa model yang dibuat merupakan good fitting.

\section{SIMPULAN}

Berdasarkan penelitian yang telah dilakukan, maka dapat disimpulkan bahwa algoritme C4.5 dapat digunakan untuk memprediksi penanaman cabai dengan menggunakan beberapa teknik seperti cross validation untuk splitting data dan juga confussion matrix untuk melihat hasil prediksi.

Hasil penelitian yang telah dilaksanakan menggunakan algoritma C4.5 diterapkan dengan eksperimen menggunakan $k$-fold cross validation dengan jumlah $\mathrm{k}=10$, maka dari itu pengujian ini memiliki 10 skenario pengujian dan 10 skenario pembagian dataset. Pembagian dataset menghasilkan nilai akurasi, precision, recall, flscore yang berbeda-beda tiap pembagian datanya dengan kata lain pembagian data berpengaruh terhadap hasil dari algoritma C4.5. Performansi algoritma C4.5 diukur menggunakan nilai akurasi, 
precision, recall, flscore. Pengujian 10 skenario tersebut menghasilkan tingkat akurasi rata-rata yaitu 0.9944444, precission mendapatkan skor rata-rata 0,989331436, recall mendapatkan nilai rata-rata 1 dan f1score mendapatkan nilai rata-rata 0,994557571. Berdasarkan model yang sudah di buat maka dilakukan pengujian prediksi menggunakan rule yang sudah tercipta dari pohon keputusan dan juga pengujian menggunakan data validasi (data yang tidak dilatih oleh model) sebanyak 95 data dan menghasilkan prediksi yang baik dengan 93 data terprediksi benar dan 2 yang salah dan jika di hitung akurasi dari prediksi tersebut menghasilkan akurasi sebesar 0,978947368

\section{DAFTAR PUSTAKA}

[1] Hamid, A. (2020, November 25). AACI sebut kurangnya pasokan jadi penyebab kenaikan harga cabai merah. Industri Kontan. Available: https://industri.kontan.co.id/news/aacisebut-kurangnya-pasokan-jadipenyebab-kenaikan-harga-cabaimerah.

[2] Suhanto. (2020, November 25). Harga cabai yang melambung diprediksi bertahan hingga akhir februari. Nasional Kontan. Available: https://nasional.kontan.co.id/news/har ga-cabai-yang-melambung-diprediksibertahan-hingga-akhir-februari

[3] Suhariyanto. (2020, Februari 3) BPS: Inflasi Januari 0,39 persen dipengaruhi kenaikan harga cabai. Bisnis Tempo. Available:

https://bisnis.tempo.co/read/1302831/b ps-inflasi-januari-039-persendipengaruhi-kenaikan-harga-cabai.

[4] M. Nukman Ridho, \& Nur Edy S., "Pengaruh perubahan iklim terhadap produktivitas tanaman cabai rawit (Capsicum frutescens L.) di
Kabupaten Malang the effect of the climate change on cayenne pepper (Capsicum frutescens L.) productivities in Malang Regency," Jurnal Produksi Tanaman, vol. 8, no. 3, pp. 304-314, 2020.

[5] H. Imtiyaz, B. H. Prasetio, and N. Hidayat, "Sistem Pendukung Keputusan Budidaya Tanaman Cabai Berdasarkan Prediksi Curah Hujan," J-PTIIK, vol. 1, no. 9, pp. 733-738, 2017.

[6] Sumbar. (2018, April 24). Budidaya Tanaman cabai. Sumbar Litbang. Available:

https://sumbar.litbang.pertanian.go.i d/index.php/info-tek/1267-

budidaya-tanaman-cabai http://sumbar.litbang.pertanian.go.id [7] D. Rosdiana and A. H. Rismayana, "Prediksi waktu tanam cabai menggunakan algoritma c4.5," SINTAK, pp. 436-442, 2018.

[8] Y. Mardi, "Data Mining: Klasifikasi Menggunakan Algoritma C4.5," J. Edik Inform., vol. 2, no. 2, pp. 213219, 2017.

[9] E. P. Cynthia and E. Ismanto, "Metode Decision Tree Algoritma C.45 Dalam Mengklasifikasi Data Penjualan Bisnis Gerai Makanan Cepat Saji," Jurasik (Jurnal Ris. Sist. Inf. dan Tek. Inform., vol. 3, no. July, pp. 1-13, 2018, doi: 10.30645/jurasik.v3i0.60.

[10] Tim Pengendalian Inflasi Pusat (TPIP). (2020, Januari 20) Koordinasi pengendalian inflasi tahun 2020. Bank Indonesia. Available: https://www.bi.go.id .https://www.bi.go.id/id/moneter/ko ordinasi-pengendalianinflasi/highlight news/Pages/Analisis-Inflasi-Januari2020.aspx. 